\title{
O QUE PENSAM OS ADOLESCENTES SOBRE O AMOR E O SEXO? UM ESTUDO NA PERSPECTIVA DAS REPRESENTAÇÕES SOCIAIS
}

\author{
WHAT DOES ADOLESCENTS THINK ABOUT LOVE AND SEX? \\ A STUDY ON SOCIAL REPRESENTATION PERSPECTIVE
}

\author{
Vanuzia Costa \\ Universidade Federal de Sergipe, Aracajú, Brasil \\ Sheyla Christine Santos Fernandes \\ Universidade Federal de Alagoas, Maceió, Brasil
}

\section{RESUMO}

O objetivo deste estudo foi compreender as representações sociais do amor e do sexo para adolescentes de uma capital do nordeste na perspectiva das representações sociais, além de analisar as relações destas representações com os dados sócio-demográficos. Participaram do estudo 301 adolescentes com idade entre 12 e 18 anos, 57\% do sexo feminino, $43 \%$ masculino. Para coleta de dados, foi utilizado um questionário sócio-demográfico e um teste de associação livre de palavras, utilizando como palavras-estímulo "amor" e "sexo". A categorização dos dados em torno de eixos temáticos apontou companheirismo, carinho e sentimento como representações do amor; e prazer, sentimento e prevenção como representações do sexo. Os resultados demonstraram que as mulheres representam o amor e o sexo mais vinculados a sentimentos; os adolescentes mais jovens e de nível escolar mais baixo representam o amor vinculado a companheirismo e o sexo a prevenção.

Palavras-chave: adolescência; amor; sexo; representações sociais.

\begin{abstract}
The aim of this study was to understand the social representations of love and sex to teenagers from a northeastern capital city and analyze the relations between socio-demographic data and these representations. 301 adolescents took part in this study ranging from 12 and 18 years old (57\% females and $43 \%$ males). The data was collected using a socio-demographic questionnaire and the word free association test about two incentive words, "love" and "sex". The categorization of the data around the thematic axis pointed to fellowship, care and feeling as a representation of love, and pleasure, feeling and prevention as the representations of sex. The data showed that women represents the love and sex more associated to feelings; the younger adolescents and the school-level lower represent the love associated to companionship and sex to prevention.
\end{abstract}

Keywords: adolescence; love; sex; social representations.

As transformações que ocorreram nas últimas décadas em decorrência do aperfeiçoamento de técnicas ou inovações no campo científico contribuíram de forma significativa para uma grande transformação da sociedade. A globalização efetivada pelo aprimoramento dos meios de comunicação trouxe efeitos decisivos no contexto social, prescrevendo novas formas de representar o mundo, de pensar e de se comportar (Moscovici, 2004).

Um grupo atravessado intimamente pelas consequências destes novos modelos é o de jovens (Dias \& Teixeira, 2010; Erikson, 1987; Nicolaci-da-Costa, 2005), tendo em vista sua alta articulação com as inovações e constante busca de experiências. Não obstante, não é esse o único grupo atingido, mas a inquietação quanto a esses novos padrões provoca reações em todas as camadas, assim como vem despertando em estudiosos um vasto interesse no campo de pesquisas.

Leal e Knauth (2006) defendem que de forma enfática o campo relacional da construção da subjetividade e dos padrões de comportamento tem base na vida social dada pela cultura e o contexto como um todo, sendo o período da adolescência um momento singular e crucial de experimentação e apreensão dos modelos veiculados pelo meio.

Essas considerações fazem emergir questões diversas no âmbito da psicologia social que se interessa pelo desenvolvimento em relação às estruturas sociais. Especificamente, para este estudo, duas são as questões 
de interesse: (a) de que forma são articulados os significados sociais dirigidos a duas modalidades de interação interpessoal (amor e sexo) na fase da adolescência? e (b) como esses repertórios se estabelecem diante de seu período de transição e das relações entre os gêneros?

A seguir, os dois conceitos centrais abordados neste estudo são desenvolvidos. Inicialmente, é apresentada uma breve caracterização da adolescência, seguida da apresentação da delimitação teórica que tem como base a Teoria das Representações Sociais, e, por fim, um estudo empírico que busca compreender as representações sociais do amor e do sexo em adolescentes e sua relação com o gênero.

\section{Adolescência: breve caracterização}

Alguns autores que trabalham com a temática da adolescência (Becker, 2003; Carvajal, 2001, dentre outros) referem que essa é uma fase compreendida como a transição da infância para a fase adulta, caracterizada como a de maior mudança quantitativa e qualitativa da vida, pois os adolescentes têm que dar conta da explosão que ocorre em nível biológico, psicológico e social (Bee, 2003; Dias \& Teixeira, 2010).

Do ponto de vista biológico denominado puberdade, as mudanças são universais, partindo do surgimento das características físicas que os prepara para a função reprodutiva (Becker, 2003; Palácios \& Oliva, 2004). No que se refere às questões de ordem psicossocial, em virtude de existir grande diversidade cultural, cada sociedade terá seu padrão de manifestação dos comportamentos e sentimentos, sendo difícil estabelecer um padrão do comportamento adolescente universal (Becker, 2003; Traverso-Yépez \& Pinheiro, 2002).

O processo de "adolescer" vai se diferenciar de acordo com a cultura, com o processo de socialização e de interação social em que o adolescente vai, aos poucos, adotando os parâmetros sociais valorizados culturalmente e fazendo as adaptações necessárias a suas exigências pessoais. Dayrell (2003) argumenta que o sujeito não cria a cultura, é introduzido nela, pois ao nascer, "a sociedade já tinha uma existência prévia, histórica, cuja estrutura não dependeu desse sujeito, portanto, não foi produzida por ele" (idem, p. 43).

Discutindo sobre a construção da identidade, Oliveira (2006) destaca que essa ocorre de forma dialética entre o objetivo e o subjetivo, o real e o imaginário, na ancoragem do sujeito em interação com o meio social através da narrativa, que é o principal elo de ligação do sujeito em sociedade. Para a autora, a construção da identidade "é o arranjo que se produz na internalização/ externalização ativa de experiências capitalizadas em diferentes esferas da vida cultural e se expressa nas práticas narrativas" (Oliveira, 2006, p. 432).
Para Levisky (1998), a capacidade de se perceber num passado histórico de existência, identificar-se num presente como pertencente a um grupo, uma família, uma sociedade e diferenciar-se dela é a tarefa primordial do adolescente buscando saída da dependência afetiva para outras qualidades de afeto e reconhecimento social. Desse modo, a identidade se constitui de um equilíbrio dinâmico entre as instâncias internas e externas do sujeito responsável por desenvolver a capacidade de se perceber enquanto ser individual e social, diferenciando-se dos demais e orientando o comportamento (Osório, 1992; Piaget \& Inhelder, 1976).

Outro fator que merece destaque no período da adolescência é a sexualidade. De modo geral, comunga-se a ideia de que a sexualidade é um dos aspectos mais importantes da vida e que está presente em todas as etapas da vida, assim como sua expressão se modifica ao longo da existência e da influência do meio social. Com efeito, desde a década de sessenta, o culto à sexualidade proposto pela modernidade conduziu os adolescentes ao desenvolvimento das fantasias sexuais cada vez mais precoces. Isso trouxe grande preocupação aos adultos, pois, agregada a essa precocidade, está a precariedade de informações para que os adolescentes possam de fato assumir um corpo sexuado. Essa falta ou insuficiência de informações se estende em todas as classes e esferas sociais. A família, quando fala sobre sexo, se detém nos anticonceptivos e preservativos. A escola, mesmo que tente abordar a sexualidade em seus currículos, não consegue dar conta das ansiedades contidas nessa fase. A mídia, por sua vez, aborda o tema através da vulgarização dos corpos com apelos sexuais (Cavajal, 2001).

Quando na puberdade a ação hormonal e as características secundárias manifestam-se, a genitalidade passa a dominar as aspirações e conduta dos adolescentes (Outeiral, 1994) que, diante desse conflito e ambivalência de informações e apelos, iniciam a atividade sexual cada vez mais precocemente (Carvajal, 2001; Outeiral, 1994; Saldanha et al., 2008). Ajuriaguerra (1983) enfatiza que, para a compreensão da sexualidade, as regras socioculturais referentes às proibições ou às permissividades devem ser consideradas.

Desse modo, em nossa sociedade, a partir da liberação da sexualidade e dos métodos contraceptivos, a sexualidade pôde ser exercida fora do contexto matrimonial e reprodutivo, passando a se configurar como uma experiência interpessoal indispensável nos relacionamentos (Bozon, 2004; Rieth, 2002). Percebe-se, desse modo, que a noção de que indivíduo e sociedade são interligados e mutuamente dependentes em todos os aspectos inerentes à vida é enfatizada.

Com efeito, uma teoria que apresenta os pressupostos norteadores das crenças, comportamentos, ati- 
tudes e escolhas como fundamentalmente apreendidos na interação do indivíduo com o mundo é a Teoria das Representações Sociais (TRS). Por meio da comunicação oriunda da coletividade e do compartilhamento de representações, as pessoas estabelecem seus repertórios, significados e sentidos, participando ativamente do processo de construção de si e da sociedade (Martins, Trindade, \& Almeida, 2003). O próximo tópico desenvolve melhor a definição e os pressupostos desta teoria.

\section{Teoria das Representações Sociais (TRS): marco teórico do estudo}

O método de investigação embasado na TRS é muito difundido pela Psicologia Social (Assis et al., 2003), tendo em vista que oferece ao pesquisador a oportunidade de apreender a realidade onde o fenômeno se elabora, difunde e é compartilhado nas práticas cotidianas (Jodelet, 2001; Moscovici, 2004). As representações sociais são o resultado do modo como os atores sociais representam um objeto e do significado que esse objeto tem em suas vidas (Assis et al., 2003). Segundo Minayo (1994), as representações sociais não são necessariamente conscientes: elas percorrem o legado social, como algo anterior e habitual, que se reproduz e se manifesta a partir das estruturas e das relações interpessoais e intergrupais. Desse modo, as representações sociais são fenômenos comuns em todas as sociedades utilizados para a produção de sentido sobre um objeto através da comunicação e experiência cotidiana (Alves-Mazzotti, 2008).

Segundo Moscovici (2004), as representações sociais são convenções na medida em que são aceitas por todos no grupo como formas de proceder e agir no convívio social, assim como são prescritivas, pois antes do sujeito nascer, já existe uma tradição que decreta o que deve ser pensado. Assim, as representações sociais não são um modo independente de pensar, elas nos são impostas com a socialização, restando ao sujeito repensar, recitar e reapresentar esses fenômenos que são essencialmente uma marca social.

De acordo com a TRS, o sujeito parte de uma representação simbólica do objeto, integrando novos significados que são partilhados no campo social. Para tanto, Moscovici (2004) descreve dois processos básicos intrinsecamente ligados: a ancoragem e a objetivação.

A ancoragem se refere ao processo de categorizar um objeto estranho para que este adquira características conhecidas dando-lhe um nome, atribuindo-lhe um significado novo, pois o estranho é assustador, insuportável e não comunicável. Mas, na medida em que este objeto é categorizado, sai do anonimato e é incorporado na matriz identitária da cultura. Moscovici (2004) afirma que o ato de categorizar alguém ou alguma coisa não significa incorporar algo de novo no repertório do sujeito, mas encaixá-lo entre algo que lhe seja familiar para que se possa ter uma relação ou familiaridade, seja de forma positiva ou negativa com esse objeto.

Se a ancoragem consiste em criar uma imagem do objeto, na objetivação dá-se um significado para que este se torne real, preenchendo a lacuna entre a comunicação e o que ela representa. No pensamento de Moscovici (2004), as representações sociais referem um processo de transformação das palavras em objetos, e, para que esses se tornem reais, é necessário que este objeto tenha um significado para o sujeito que o representa. Associando esses processos de ancoragem e objetivação, percebe-se que, ao se falar em representações sociais, fala-se de um processo sociocognitivo que une o sujeito, o objeto e a realidade circundante através das experiências comuns a todos os membros de uma sociedade, pois é do contato com meio social que os atores se apropriam das imagens, da linguagem e comportamentos necessários para a familiaridade com o corpo social.

A formação de uma representação enquanto organização de conhecimento implica uma ação ao mesmo tempo individual e coletiva, em que os indivíduos apropriam-se e reorganizam os modos de pensamento e as representações consolidam-se subjetivamente passando, então, a compor suas interpretações de mundo, de si mesmo e influenciando em suas práticas cotidianas. Não existe história sem sujeitos, nem sujeitos sem história; os indivíduos são produto da interação com o meio social e cultural (Alves-Mazzotti, 2008; Jovchelovitch, 1998, 2004; Moscovici, 2004; Spink, 2004).

Nesse sentido, Espindula e Santos (2004) alegam que, entre outras funções, as representações sociais servem de referenciais de ação aos indivíduos em seu ambiente. Desse modo, a apreensão das representações sociais do amor e do sexo entre os adolescentes ganha relevância e sentido, possibilitando a compreensão da realidade atual desse grupo em nível intrapessoal, interpessoal e intergrupal, pois elas auxiliam os sujeitos na aplicação do conhecimento social disponível que transcende os limites da sua experiência.

Assim, o objetivo deste estudo foi compreender as representações sociais do amor e do sexo em adolescentes, analisando as relações entre os dados sociodemográficos e essas representações.

\section{Método}

Adotando o critério estabelecido pelo Estatuto da Criança e do Adolescente - ECA(Lei n. 8069, 1996), que concebe $\mathrm{o}$ adolescente como a faixa etária correspondente entre 12 e 18 anos de idade, contou-se com a participação 
voluntária de 301 adolescentes, solteiros, de ambos os sexos $(57 \%$ do sexo feminino e $53 \%$ do sexo masculino), com idade variando entre 12 e 18 anos (Média de idade $=14 ; \mathrm{DP}=1,569$ ), estudantes de duas escolas (sendo $59,1 \%$ de uma escola pública e 40,9\% de uma escola privada) da cidade de Aracaju, Sergipe. A escolaridade dos estudantes contemplou o ensino fundamental $\left(7^{\circ}, 8^{\circ}\right.$ e $9^{\circ}$ anos) e o ensino médio ( $1^{\circ}, 2^{\circ}$ e $3^{\circ}$ anos).

Utilizou-se um questionário com dados sociodemográficos (por exemplo, sexo, idade, escolaridade dos sujeitos) e a técnica de Associação Livre de Palavras em formato escrito por ser "um instrumento que se apóia sobre um repertório conceitual, permitindo a unificação dos universos semânticos e a saliência de universos de palavras comuns diante de estímulos indutores utilizados no estudo" (Castanha, Coutinho, Saldanha, \& Ribeiro, 2007, p. 123). No questionário, abaixo dos dados sociodemográficos, cinco linhas foram utilizadas para as respostas suscitadas pela indução da pesquisadora. Como estímulos indutores, foram utilizadas as palavras (a) Amor e (b) Sexo. Para Gil (1999) e Castanha et al. (2007), a apresentação de uma situação estimulante suscita no indivíduo respostas nos níveis objetivo e subjetivo sobre o fenômeno pesquisado, e cuja interpretação das respostas revela a visão de mundo dos sujeitos envolvidos na pesquisa (neste caso, os adolescentes).

Toda a investigação foi realizada dentro dos princípios éticos contidos na Resolução 196/96 do Conselho Nacional de Saúde (Conselho Nacional de Saúde, 1999), atendendo aos seguintes aspectos: o consentimento das instituições e dos sujeitos da pesquisa, assegurando-lhes o sigilo, anonimato e respeito aos seus valores culturais, morais, sociais, religiosos e éticos, resguardando às autoras do projeto a propriedade intelectual dos dados e a divulgação pública dos resultados.

A partir dos critérios de inclusão (estar na faixa etária dos 12 aos 18 anos e espontaneidade em participar), bem como do preenchimento do primeiro item referente aos dados sociodemográficos, foi realizada uma simulação da técnica de associação de palavras, apresentando um estímulo aleatório aplicado coletivamente para familiarizar os participantes com o instrumento utilizado. Após esse procedimento, deu-se sequência à pesquisa, solicitando-se aos adolescentes que escrevessem no espaço apropriado cinco palavras que lembravam ao ouvir a expressão indutora "amor" (Quando falo a palavra "amor" quais as palavras que lhe vêm à mente? Repetindo o procedimento com $\mathrm{o}$ outro estímulo - "sexo).

Após a coleta de dados, o passo seguinte consistiu na categorização das palavras (Minayo, 1994) evocadas em torno de eixos temáticos que expressavam o mesmo sentido, conteúdo e carga emocional, sendo analisado primariamente pelas pesquisadoras e posteriormente por quatro profissionais de áreas distintas: psicologia, fisioterapia e exatas, que atuaram como experts, gerando um índice de concordância de $90 \%$. Os dados foram analisados posteriormente através da utilização do pacote estatístico SPSSWIN 15.0, sendo realizadas análises descritivas e de correlação para atingir os objetivos propostos pelo presente estudo.

\section{Resultados e discussão}

Em busca de compreender as representações do amor e do sexo que permeiam as relações dos adolescentes e cujos significados são subjetivados na constituição de sentidos, este trabalho foi desenvolvido partindo dos pressupostos da TRS. Solicitados a apontar as cinco palavras que surgissem à mente a partir dos estímulos indutores, para o estímulo amor os adolescentes evocaram 228 palavras e para o estímulo sexo, 275 palavras. O processo de categorização norteou a redução desses grupos em torno de 12 eixos temáticos, conforme descritos nas Tabelas 1 e 2, utilizando como critério de exclusão os escores de palavras com evocação inferior a $1 \%$ que não se encaixavam nessas categorias.

Tabela 1: Categorias, eixos temáticos e exemplos de evocações da palavra amor

\begin{tabular}{|c|c|c|}
\hline Categoria & Eixo temático & Evocações \\
\hline Companheirismo & Palavras relacionadas a atitudes e valores nas relações interpessoais & $\begin{array}{l}\text { Companheirismo, respeito, } \\
\text { amizade, confiança, fidelidade }\end{array}$ \\
\hline Carinho & Relaciona-se com o comportamento direcionado ao outro através do toque & Beijar, abraçar, carinho \\
\hline Sentimento & $\begin{array}{l}\text { Revela a percepção quanto aos atributos afetivos dos adolescentes nas } \\
\text { relações interpessoais }\end{array}$ & $\begin{array}{l}\text { Afeto, coração, paixão, emo- } \\
\text { ção, gostar }\end{array}$ \\
\hline Relacionamento & Experiência de união com parceiro, pressupondo um compromisso estável & Namoro, noivado, casamento \\
\hline Família & $\begin{array}{l}\text { Indica evocações relacionadas ao universo particular do adolescente em } \\
\text { suas relações familiares }\end{array}$ & Mãe, pai, avós, irmãos \\
\hline Desejo & Expressa o amor relacionado à sexualidade do adolescente & $\begin{array}{l}\text { Atração, tesão, sexo, cama, } \\
\text { transa }\end{array}$ \\
\hline
\end{tabular}


Sofrimento

Expressa características negativas de ansiedade em relação ao amor

Felicidade

Características de bem-estar nas relações amorosas em geral

Essencial

Atitudes e valores ético-político-morais positivos e valorizados socialmente

Compreensão

Experiência de aceitação das diferenças entre as pessoas e grupos

Gênero

Pressupõe o envolvimento com o parceiro do sexo oposto ou da relação heterossexual

Diversão
Indica o desejo de companhia para atividades relacionadas ao lazer
Tristeza, complicação, traição, desentendimento, brigas

Alegria, prazer, satisfação, bom, sorriso

Fraternidade, solidariedade, humanidade, esperança

Tolerância, compreensão

Homem, mulher, menino menina

Passear, curtir, sair, festas
De acordo com o agrupamento de palavras em torno dos eixos temáticos, percebe-se que a representação do amor na visão desse grupo está pautada primeiramente (em $64,8 \%$ dos participantes) pelas evocações companheirismo, respeito, amizade e confiança. Em seguida, concebem-se as representações ligadas ao contato mais íntimo (em 54,8\% dos participantes) das evocações abraço, beijo, carinho e as evocações referentes ao sentimento, como afeto, coração, paixão (em $42,2 \%$ dos participantes). O relacionamento como representação do amor vem em seguida (citado em $42,2 \%$ das evocações), representadas pelas palavras namoro, noivado, casamento.

De acordo com Almeida (2004), a afinidade, admiração e união entre os pares fornece o contexto no qual nasce o amor. Resultados semelhantes também foram encontrados por Bertoldo e Barbara (2006): no núcleo central das representações sobre o namoro, foram citados os elementos amor, carinho, companheirismo, amizade e compromisso. Essas categorias, conforme aponta Giddens (1993), são constituintes do relacionamento puro, centrado no compromisso, intimidade e na confiança, ofertando aos parceiros certas garantias de estabilidade, ao passo que a união deva durar somente enquanto for satisfatória para ambos.

Percebe-se que os elementos se ligam através de um continuum, configurando-se numa relação com a garantia de estabilidade e segurança para os cônjuges. Além disso, o alicerce do amor talvez esteja relacionado à experiência mútua, o compartilhar de experiências: "estas formas de comunhão psicológica naturalmente só ocorrem ao longo de certo tempo, nunca em reações à primeira vista" (Pereira, 1982, p. 2).

Também se puderam observar representações do amor que não se dirigem necessariamente ao outro como objeto de desejo, mas como uma relação de amizade baseada nos mesmos princípios sem se constituir em um relacionamento íntimo. Como exemplo, as representações do amor articuladas na categoria família, referente a $37,5 \%$ das evocações, emergiram, sobretudo, pelos adolescentes distribuídos no grupo de menor idade (12 aos 14 anos). Alguns autores (Becker, 2003; Carvajal, 2001) afirmam que, no início da adolescência, ainda existe um elo de ligação muito forte entre o adolescente e a família, pois os adolescentes ainda concentram na família o modelo de identificação e, à medida que se aproxima e expande o contato com outros grupos, há um distanciamento, para que o adolescente possa consolidar os elementos constitutivos de sua personalidade.

A categoria desejo, representada por $24,9 \%$ das evocações, agregou representações que expressam a ideia de amor relacionado à sexualidade. Segundo Almeida (2004), o que se solicita ao objeto de escolha é que seja essencialmente um fator de satisfação; nesse sentido, a satisfação foi vinculada à sexualidade. A categoria felicidade, citada por $18,6 \%$ dos adolescentes, também como sendo algo essencial para se compor o amor, aparece atrelada a um relacionamento movido pelo desejo de completude e prazer. Retomando a noção de relacionamento puro citado em Giddens (1993), nota-se que a reciprocidade aparece como algo essencial do amor.

Assim como as representações positivas relacionadas ao amor, o sofrimento, categoria referente a 19,3\% das evocações, também foi citado por uma parcela de adolescentes. Carvajal (2001) e demais autores (Dayrell, 2003; Osorio, 1992) argumentam que os apelos e a exploração da sexualidade pela mídia incentivam os adolescentes à precocidade da iniciação da vida amorosa sem que tenham a maturidade psíquica suficiente para manejar as demandas de um relacionamento, sendo um dos principais motivos para que essas demandas se tornem mais angustiantes que gratificantes. Esses dados confirmam os resultados da pesquisa realizada por Nóbrega, Fontes e Paula (2005), em que o sofrimento dos jovens em relação ao amor se fundamenta na experiência de rejeição, traição e solidão.

As categorias essencial, com $11,3 \%$ das evocações, e compreensão, com 10,3\%, cuja frequência maior de evocação se deu no grupo de adolescentes com idade mais elevada (dos 15 aos 18 anos), sugerem que esses já alcançaram um grau maior de maturidade e indivi- 
duação, tanto no que diz respeito a um relacionamento mais centrado no compromisso conforme a proposta de relacionamento descrita por Giddens (1993), assim como abrange outros fatores possíveis de se atrelar a um sentimento, como nas evocações de caráter mais universais citadas na categoria essencial (fraternidade, solidariedade, humanidade). Também se pode agregar a esse grupo de idade a categoria diversão, citada por $10 \%$ dos participantes, tendo em vista que deste grupo partiu o maior contingente de evocações.

A categoria descrita como gênero, com 10,3\% das evocações, corresponde apenas à descrição psicossociológica dos sexos masculino e feminino, não se pretendendo estabelecer nenhuma relação de poder per si. A descrição dessa categoria vinculada à relação heterossexual partiu da própria evocação dos adolescentes em demonstrar a normatização da sexualidade. Para essa categoria, as palavras mais citadas referiam o amor através de termos ligados ao sexo oposto do respondente (por exemplo: homem, garoto, menino [evocados pelas respondentes do sexo feminino] e mulher, garota, menina [evocados pelos respondentes do sexo masculino]). Conforme Silva (2006), heterossexualidade possui uma denominação básica como sendo a sociedade dividida entre homens e mulheres, representação que é possível de se verificar pelas evocações referidas nessa categoria.

Para a representação do sexo, foram evocadas 275 palavras diante do estímulo (Tabela 2).

Tabela 2: Categorias, eixos temáticos e exemplos de evocações da palavra sexo

\begin{tabular}{|c|c|c|}
\hline Categoria & Eixo temático & Evocações \\
\hline Prazer & Corresponde ao grau de satisfação pessoal com o ato sexual & $\begin{array}{l}\text { Felicidade, gozo, satisfação, } \\
\text { orgasmo, êxtase }\end{array}$ \\
\hline Sentimento & $\begin{array}{l}\text { Engloba ao evocações relacionadas aos atributos afetivos que os adoles- } \\
\text { centes representam para a relação sexual }\end{array}$ & Amor, paixão, gostar, coração \\
\hline Prevenção & $\begin{array}{l}\text { Esta categoria demonstra o nível de cognição que os adolescentes têm em } \\
\text { relação à prevenção no tocante à gravidez, como também à prevenção de } \\
\text { doenças sexualmente transmissíveis }\end{array}$ & $\begin{array}{l}\text { Preservativo, camisinha, prote- } \\
\text { ção, anticoncepcional, preven- } \\
\text { ção, DSTs, AIDS, }\end{array}$ \\
\hline Desejo & $\begin{array}{l}\text { Parte da fantasia própria de cada adolescente em relação à idealização do } \\
\text { outro }\end{array}$ & $\begin{array}{l}\text { Malícia, instinto, curiosidade, } \\
\text { querer, fantasia, sedução }\end{array}$ \\
\hline Cumplicidade & $\begin{array}{l}\text { Esta categoria descreve a reação dos adolescentes na valorização do conta- } \\
\text { to com o parceiro e das atitudes valorativas dessa relação }\end{array}$ & $\begin{array}{l}\text { Atenção, sinceridade, troca, } \\
\text { companheirismo, cuidado }\end{array}$ \\
\hline Relacionamento & $\begin{array}{l}\text { Pressupõe que para haver o ato sexual, deve haver um compromisso entre } \\
\text { os parceiros }\end{array}$ & $\begin{array}{l}\text { Casamento, sério, núpcias, con- } \\
\text { vivência, compromisso }\end{array}$ \\
\hline Relação & Expressa o sexo como uma prática normal entre os sexos & $\begin{array}{l}\text { Transa, prática, sexualidade, } \\
\text { disposição, corpos }\end{array}$ \\
\hline Carinho & Relaciona-se com o comportamento direcionado ao outro através do toque & $\begin{array}{l}\text { Abraço, beijo, sensibilidade, } \\
\text { ternura }\end{array}$ \\
\hline Gravidez & $\begin{array}{l}\text { Nesse eixo, foram agrupadas as palavras que expressavam o sexo associa- } \\
\text { do à procriação }\end{array}$ & $\begin{array}{l}\text { Reprodução, procriação, filho, } \\
\text { fecundação }\end{array}$ \\
\hline Gênero & $\begin{array}{l}\text { Transmite a ideia de uma relação heterossexual, podendo ser percebida } \\
\text { quando o feminino se refere ao masculino e o masculino se refere ao } \\
\text { feminino }\end{array}$ & $\begin{array}{l}\text { Homem, mulher, menino, meni- } \\
\text { na, gato, gata }\end{array}$ \\
\hline Maturidade & $\begin{array}{l}\text { Refere-se a valores morais proveniente da socialização e da educação } \\
\text { sexual }\end{array}$ & $\begin{array}{l}\text { Preparação, amadurecimento, } \\
\text { informação, princípios, consci- } \\
\text { ência }\end{array}$ \\
\hline Orgia & $\begin{array}{l}\text { Pressupõe uma prática sexual instintiva, sem necessidade de envolvimento } \\
\text { afetivo }\end{array}$ & $\begin{array}{l}\text { Diversão, safadeza, pegação, } \\
\text { aventura, suruba }\end{array}$ \\
\hline
\end{tabular}

No que se refere ao sexo, Almeida (2004) afirma que, na escolha do parceiro, além de estar disponível, o que se procura é o prazer, e é condizente com esse pensamento que as palavras mais evocadas pelos adolescentes para representar o sexo (em $60,8 \%$ das evoca- ções) se articularam à categoria prazer (ex.: felicidade, gozo, orgasmo etc). As categorias sentimento (59,5\% das evocações), cumplicidade (33,6\% das evocações), relacionamento (30,9\% das evocações), carinho (26,6\% das evocações), gênero ( $22,9 \%$ das evocações), e desejo 
(33,9\% das evocações) já foram comentadas no contexto do amor e serão retomadas mais adiante.

Como representação social do sexo, algumas categorias que refletem temores relativos a essa prática também emergiram. As categorias prevenção (41,5\% das evocações) e gravidez (23,3\% das evocações) representam a percepção de perigo ou ameaça. No discurso dos sujeitos deste estudo, percebe-se que esses adolescentes possuem informações a respeito da prevenção e do seu significado no decurso de suas vidas e de seu futuro, indicando que a configuração da prevenção como algo importante relativo ao sexo faz parte dos seus repertórios representacionais. Esse dado é consistente com pesquisas recentes que vêm demonstrando que existe uma tendência ao incremento da proteção contra as DSTs por parte dos jovens (Paiva, Calazans, Venturi, \& Dias, 2008).

Sobre a prevenção, Rieth (2002) e Silva (2002) mencionam que, entre os meninos, é frequente o uso de preservativos quando se trata de parceiras eventuais, mas num relacionamento fixo, onde predomina a confiança, esse método é deixado de lado. Para as adolescentes, a prevenção é um dilema, tendo no método contraceptivo mais citado o anticoncepcional, uma ameaça à autoimagem pelo fato de ser representado como causa do aumento do peso corporal. No entanto, há um consenso entre os sexos que, se existe um relacionamento, o preservativo esfria a relação e o não uso é uma prova de fidelidade cuja totalidade amor-sexo aumenta o vínculo entre os parceiros.

É importante destacar que os dados sobre a prevenção das DSTs e gravidez na adolescência são controversos. Enquanto pesquisas nacionais apontam que é crescente a quantidade de jovens que se previnem sistematicamente nas relações sexuais (Paiva et al., 2008), pesquisas restritas a determinados contextos apontam o contrário. Por exemplo, em uma ampla pesquisa realizada na Paraíba, a maior parte dos jovens relatou não usar preservativo em suas relações sexuais (Saldanha et al., 2008). Dado semelhante foi encontrado na capital de Mato Grosso (Carleto, Faria, Martins, Souza, \& Matos, 2010). O que pode estar por trás desses dados possivelmente está relacionado à incongruência entre as representações ideológicas e o comportamento real dos adolescentes no que se refere à sexualidade: eles conhecem e sabem da importância dos cuidados pertinentes a uma vida sexual ativa, mas na prática ainda é preliminar a efetivação deste saber em práticas comportamentais, o que enfatiza a importância de políticas públicas voltadas à solução desta problemática.

$\mathrm{Na}$ categoria relação $(27,6 \%$ das evocações), percebe-se que a intimidade da relação sexual é uma prática comum entre pessoas que estabelecem um relacionamento, resultados consistentes com outras investigações
(Bertoldo \& Barbara, 2006; Rieth, 2002). Os resultados evidenciaram também que existe uma diferenciação na percepção dos grupos de acordo com o sexo. Para as meninas, há uma estreita ligação entre sexo e sentimento, enquanto que para os meninos a relação sexual não se constitui na primazia de relações afetivas, mas no desejo e disponibilidade do outro e da situação como afirmação da virilidade, corroborando com os resultados de um conjunto de estudos (Carleto et al., 2010; Rieth, 2002; Saavedra, Nogueira, \& Magalhães, 2010).

Em relação à representação do sexo como orgia (10,6\% das evocações), os dados evidenciam o descompromisso de um sujeito em relação ao outro, denotando a ideia do prazer pelo prazer. Sobre este ponto, Biddulph (2003) argumenta que diferentes pessoas unem-se a outras por diferentes motivos, seja pela autossatisfação, medo da solidão ou rejeição, experimentação, ensaio, autoafirmação, curiosidade, exigências do grupo ou propriamente a diversão. Esses adolescentes referem nessa categoria evocações que sugerem que o sexo está relacionado a buscas diversas, um meio de gratificação imediata.

Em décadas passadas, os adolescentes tinham uma configuração da sexualidade de forma que existiam regras a serem seguidas, com papéis sociais bem definidos para esse exercício: às meninas o casamento, aos meninos a total liberdade de expressão da sexualidade. Porém, atualmente, essas regras não são tão rígidas, tanto meninos como meninas nos dias de hoje têm a possibilidade de fazer valer sua liberdade de expressão sexual que vai desde um primeiro beijo sem compromisso até a relação sexual propriamente dita, dependendo estritamente do desejo e disponibilidade dos parceiros envolvidos no processo (Silva, 2002). No entanto, é importante destacar que essa liberdade ainda carrega resquícios da moralidade antiga, sobretudo no que se refere ao comportamento feminino. Muitas adolescentes comportam estigmas pejorativos em relação à liberdade da prática sexual (Saavedra et al., 2010; Saldanha et al., 2008).

A citação da categoria maturidade $(11,6 \%$ das evocações) se configura numa forma mais elaborada de se relacionar com o outro, fruto de maior amadurecimento e respeito pelo parceiro. Pressupõe-se que esses adolescentes já alcançaram certo grau de autonomia das emoções, passando a assumir uma forma mais madura de relacionamento, procurando estabilidade emocional e planejamento do futuro ou que pelo menos inferem que são valores importantes no contexto do sexo (Oliveira, Gomes, Marques, \& Thiengo, 2007).

Tendo concluído as análises pertinentes ao conteúdo das evocações dos estudantes, passamos a verificar em que medida as representações sobre o amor e o sexo se relacionam aos dados sociodemográficos. Para tanto, 
foi realizada uma análise de correlação de Spearman. Esta análise permite encontrar associações significativas entre variáveis categóricas (Dancey \& Reidy, 2006), neste caso, entre as representações sociais do amor e do sexo e os dados sociodemográficos.

Em relação às categorias utilizadas pelos adolescentes para representarem o amor e os dados sociodemográficos, algumas correlações foram estabelecidas (Tabela 3).

Tabela 3: Correlação entre as representações sociais acerca do amor e o gênero

\begin{tabular}{lccc}
\hline \multicolumn{1}{c}{ Categorias } & \multicolumn{3}{c}{ Dados psicossociais } \\
\cline { 2 - 4 } & Sexo & Idade & Escolaridade \\
\hline Companheirismo &,$- 261(* *)$ & - & - \\
Carinho &,$- 172(* *)$ &,$- 173(* *)$ & - \\
Família & - & - & - \\
Sentimento & - & - & - \\
Relacionamento & - &,$- 280(* *)$ &,$- 248(* *)$ \\
Sofrimento & - & - & - \\
Desejo &, $231(* *)$ & - & - \\
Felicidade & - & - &, $172(* *)$ \\
Essencial & - & - & $-169(* *)$ \\
Diversão & - & - & - \\
Gênero & - & $-157(* *)$ & - \\
Compreensão & - & & - \\
\hline Nota: ** $>0.01$ & & & -
\end{tabular}

Pode-se observar que as mulheres usam mais os termos companheirismo e carinho para representar o amor, valorizando mais os laços afetivos, esperando construir relacionamentos duradouros, enquanto os homens encontram o seu significado na palavra desejo, não estando associado necessariamente ao afeto, mas envolvendo a afirmação da masculinidade.

Considerando as relações estabelecidas entre as representações sociais do amor e sexo e idade, foi encontrado que o amor para os adolescentes mais jovens (12 aos 14 anos) está mais representado pelo carinho e relacionamento, enquanto que os adolescentes entre 15 e 18 anos representam o amor principalmente pela compreensão. Percebe-se nessas correlações que os dois grupos preservam as representações contidas na síntese do relacionamento puro, em que o amor materializa-se no contato e no compromisso dos parceiros em estarem unidos, centrados no compromisso, confiança, intimidade e estabilidade no relacionamento (Giddens, 1993).

No tocante à escolaridade, os adolescentes que estão cursando o Ensino Fundamental associam o amor ao relacionamento, em busca de trocas de experiências, de companhia e criação de vínculo, enquanto os adolescentes do Ensino Médio atribuem ao amor a representação da felicidade e de características universais que tornam a convivência social possível, como solidariedade e fraternidade, estando desprovido de fundamentos da união romântica.

No que se refere à análise das relações entre as representações sociais do sexo e os dados sociodemográfi$\cos$, apenas a categoria prazer não apresentou correlação significativa com o gênero, a idade e a escolaridade dos participantes, o que pode indicar que independente das diferenças de gênero, idade e escolaridade, o prazer está associado ao sexo (Tabela 4).

Tabela 4: Correlação entre as Representações acerca do Sexo e os dados psicossociais

\begin{tabular}{lccc}
\hline \multirow{2}{*}{ Categorias } & \multicolumn{3}{c}{ Dados psicossociais } \\
\cline { 2 - 4 } & Sexo & Idade & Escolaridade \\
\hline Prazer & - & - & - \\
Sentimento &,$- 215(* *)$ & - & - \\
Prevenção & - &,$- 348(* *)$ &,$- 369(* *)$ \\
Relacionamento & - & - &,$- 190(* *)$ \\
Desejo & - &, $129(*)$ &, $210(* *)$ \\
Cumplicidade &,$- 232(* *)$ & - & - \\
Carinho &,$- 232(* *)$ & - & - \\
Gravidez & - &,$- 260(* *)$ &,$- 390(* *)$ \\
Gênero &, $342(* *)$ & - & - \\
Maturidade & - &, $151(* *)$ & - \\
Relação &, $277(* *)$ & - & - \\
Orgia &, $159(* *)$ & - & - \\
\hline
\end{tabular}

Nota: $* *>0.01$

Os resultados demonstraram que os participantes representam o sexo de modo diferente em função do gênero. As mulheres representam o sexo como uma ação pautada em sentimento, cumplicidade e carinho, enquanto que, para os homens, o sexo é representado pelas categorias gênero, relação e orgia. Esses dados indicam que as adolescentes do sexo feminino percebem o sexo mais vinculado aos sentimentos, enquanto que os adolescentes do sexo masculino o percebem mais vinculado à prática em si e à satisfação dela proveniente. Esse achado confirma um conjunto de dados frequentemente encontrados (Camargo \& Ferrari, 2009; Rieth, 2002; Saavedra et al., 2010), no tocante aos objetivos da relação sexual diferenciada de acordo com os modelos predeterminados socialmente para homens e mulheres e cujos fundamentos são pautados na afirmação da 
virilidade e instinto masculino e na emoção feminina (L'Engle, Brown, \& Kenneavy, 2006).

No tocante à idade, percebe-se que a representação do sexo para os mais jovens (dos 12 aos 14 anos) está relacionada à prevenção das DSTs e da gravidez, e os mais velhos (dos 15 aos 18 anos) representam o sexo como o desejo e maturidade, denotando em ambos os grupos uma certa adequação ao modelo adulto de conduta em assumir a sexualidade com responsabilidade. Pode-se sugerir que as representações sobre o sexo evocadas por esses jovens indicam o evoluir de uma percepção mais madura, posto que faz menção a uma vida sexual mais cautelosa, conforme achados de estudos nacionais (Paiva et al., 2008), mas que, mesmo em vias de progressão, encontra-se muito aquém do seja esperado em termos de prevenção de DSTs e gravidez (Saavedra et al., 2010).

Em relação à escolaridade, foi encontrado que o sexo representado pelas categorias prevenção, gravidez, relacionamento e desejo está associado ao nível de escolaridade dos adolescentes. Os adolescentes do ensino fundamental, em detrimento dos adolescentes do ensino médio, representam o sexo como prevenção, gravidez e relacionamento, demonstrando uma preocupação com a prática sexual e suas consequências. Alguns autores (Rieth, 2002; Silva, 2002) referem que faz parte dos pensamentos dos jovens como um todo a associação do sexo aos riscos a ele inerentes, no entanto, a prática sexual não é reprimida em função desses riscos, uma vez que é crescente a quantidade de indicadores estatísticos que apontam as consequências negativas do sexo sem segurança, como gravidez precoce e incidência de DSTs. Esses dados refletem também que a percepção dos adolescentes sobre o sexo está muito mais vinculada a fatores positivos (como o prazer) do que aos riscos.

\section{Conclusões}

A discussão no âmbito da expressão da sexualidade na adolescência adquiriu significado especial entre pesquisadores de áreas distintas nas últimas décadas após a proliferação das DSTs e da gravidez na adolescência. Esses fatos colocaram em xeque a tão sonhada liberdade de expressão e liberação da sexualidade porque não só os adolescentes não estavam preparados para as consequências dessa liberdade como também a sociedade, a família e a escola não souberam lidar com essa contingência. Sabe-se que existe uma preocupação dos estabelecimentos de ensino em abordar a sexualidade no âmbito biofisiológico, mas essa abordagem não dá conta das demandas de ordem psicoafetivas geradas nesse contexto e tampouco a escola possui capacidade de assumir uma responsabilidade e demanda que também é de domínio familiar e social.
Ainda que este estudo tenha se pautado exclusivamente na metodologia do Teste de Associação Livre de Palavras, foi possível perceber traços de insegurança típicos do período da adolescência, através das rasuras, uso da borracha ou corretivo durante a aplicação do teste. Também foi possível observar que falar de amor e sexo não se configura uma tarefa fácil para esse grupo de adolescentes, tendo em vista o furor no momento em que foram ofertados os estímulos indutivos bem como no modo comportamental de reação quando os adolescentes escondiam suas evocações para que os colegas não pudessem vê-las, principalmente as meninas.

Interessante também elucidar que, muito embora algumas pesquisas demonstrem que na adolescência o sexo na maior parte das vezes é mais relacionado ao prazer do que aos riscos (Saldanha et al., 2008), o grupo pesquisado aponta uma preocupação quanto à prevenção das DSTs bem como da gravidez, evidenciando assim certo nível de informação dos possíveis riscos desses acontecimentos e suas consequências para o futuro. Foram apontadas também como representações do amor e sexo indicadores de responsabilidade e cautela consigo e com o parceiro, como as evocações maturidade, confiança, respeito, compreensão, dentre outras.

Assume-se que os modelos reproduzidos nos discursos e práticas aqui apresentados não se tratam de uma nova representação, mas de formas de conquista diferentes, meios de comunicação diferentes, maior liberdade de ação e interação nos relacionamentos interpessoais, tudo pautado nos valores apreendidos pelo corpo social. Embora os discursos dos adolescentes sejam diferentes, pode-se inferir que "eles lutam para mudar a realidade e ao mesmo tempo se adequam a ela" (Outeiral, 1994, p. 23).

Durante a análise dos dados, foi possível perceber que embora as representações sociais do amor e do sexo para esses adolescentes tenham sido apresentadas e relacionadas a algumas variáveis sociodemográficas, a carência de alguns pontos deve ser considerada. Por exemplo, a relação entre o adolescente e seu contexto familiar, as fontes de informações a respeito da sexualidade a que têm acesso, se já haviam iniciado a prática sexual e os sentimentos oriundos dessa experiência, além de algumas questões mais profundas referentes às formas de relacionamento experienciadas por eles. É muito importante ressaltar que, embora a crença e conduta de cada sujeito se traduzam pelo contexto sociocultural, sua atuação é única. Desse modo, é cabível não só a continuidade dessa exploração das representações sociais do amor e do sexo de modo mais específico nesse contexto, mas também em outros, a fim de contribuir de modo mais eficaz na descrição desses fenômenos.

Percebe-se, pois, que as representações sociais do amor e do sexo para os adolescentes se baseiam no 
desejo de complementaridade, não no sentido estrito da palavra, como propõe o amor romântico citado por Giddens (1993) ou do "príncipe encantado" como aponta Outeiral (1994, p. 24), mas do sujeito real e nas ações recíprocas. Assim, diferente dos resultados encontrados por Matos, Féres-Carneiro e Jablonski (2005), cujos adolescentes encontram-se situados na idealização dos sentimentos e sensações, os adolescentes situados no contexto desta pesquisa representam o amor e o sexo vinculados à proposta de satisfação mútua, com base no compromisso e desejo recíproco enquanto for satisfatório às expectativas, exigências e demandas da dupla (Giddens, 1993), ou, como enfatizou o poeta: "que não seja imortal, posto que é chama, mas que seja infinito enquanto dure" (Soneto de fidelidade, Vinícius de Moraes).

\section{Referências}

Ajuriaguerra, J. (1983). Manual de psiquiatria infantil. São Paulo, Masson.

Almeida, T. (2004). A gênese e a escolha no amor romântico: alguns princípios regentes. Revista de psicologia, 22(1-2), 9-13.

Alves- Mazzotti, A. J. (2008). Representações sociais: aspectos teóricos e aplicações à educação. Revista Múltiplas Leituras, 1(1), 18-43.

Assis, S. G., Avanci, J. Q., Silva, C. M. F. P., Malaquias, J. V., Santos, N. C., \& Oliveira, R. V. C. (2003). A representação social do ser adolescente: um passo decisivo na promoção da saúde. Ciência e saúde coletiva, 8(3), 669-679.

Becker, D. (2003). O que é adolescência (Coleção Primeiros Passos). São Paulo: Brasiliense.

Bee, H. (2003). Adolescência. In H. Bee, A criança em desenvolvimento ( $9^{\text {a }}$ ed., pp. 513-518). Porto Alegre: Artmed.

Bertoldo, R. B. \& Barbara, A. (2006). Representação social do namoro: a intimidade na visão dos jovens. PsicoUSF, 11(2), 229-237.

Biddulph, S. (2003). Por que escolhi você? São Paulo: Fundamento.

Bozon, M. (2004). Sociologia da sexualidade. Rio de Janeiro: FGV.

Camargo, E. A. I. \& Ferrari, R. A. P. (2009). Adolescentes: conhecimentos sobre sexualidade antes e após a participação em oficinas de prevenção. Ciência \& Saúde Coletiva, 14(3), 937-946.

Carleto, A., Faria, C. S., Martins, C. B. G., Souza, S. P. S., \& Matos, K. F. (2010). Conhecimento e práticas dos adolescentes da capital de Mato Grosso quanto às DSTs/AIDS. DST - Jornal brasileiro de doenças sexualmente transmissiveis, 22(4), 206-211.

Carvajal, G. (2001). Tornar-se adolescente: a aventura de uma metamorfose: uma visão psicanalítica da adolescência $\left(2^{\mathrm{a}}\right.$ ed.). São Paulo: Cortez.

Castanha, A. R., Coutinho, M. P. L., Saldanha, A. A. W., \& Ribeiro, C. G.. (2007). Avaliação da qualidade de vida em soropositivos para o HIV. Estudos de psicologia (Campinas), 24(1), 23-31.

Conselho Nacional de Saúde. (1999). Resolução 196/96 - Diretrizes e normas regulamentadoras de pesquisa envolvendo seres humanos. Acesso em maio, 2008, em http://www.ufrgs. br/bioetica/res19696.htm
Dancey, C. P. \& Reidy, J. (2006). Estatística sem matemática para psicologia usando SPSS para Windows. Porto Alegre: Artmed.

Dayrell, J. (2003). O jovem como sujeito social. Revista Brasileira de Educação, 24(3), 40-52.

Dias, A. C. G. \& Teixeira, M. A. P. (2010). Gravidez na adolescência: um olhar sobre um fenômeno complexo. Paideia, 20(45), 123-131.

Erikson, E. (1987). Identidade, juventude e crise. Rio de Janeiro: Guanabara.

Espindula, D. H. P. \& Santos, M. F. S. (2004). Representações sobre a adolescência a partir da ótica dos educadores sociais de adolescentes em conflito com a lei. Psicologia em estudo, 9(3), 357-367.

Giddens, A. (1993). A transformação da intimidade: sexualidade, amor e erotismo nas sociedades modernas. São Paulo: UNESP.

Gil, A. C. (1999). Métodos e técnicas de pesquisa social (5 $\left.5^{\mathrm{a}} \mathrm{ed}.\right)$. São Paulo: Atlas.

Jodelet, D. (2001). As representações sociais. Rio de Janeiro: EdUERJ.

Jovchelovitch, S. (1998). Representações sociais: para uma fenomenologia dos saberes sociais. Psicologia \& Sociedade, 10(1), 54-68.

Jovchelovitch, S. (2004). Psicologia social, saber, comunidade e cultura. Psicologia \& Sociedade, 16(2), 20-31.

Leal, A. F. \& Knauth, D. R. (2006). A relação sexual como uma técnica corporal: representações masculinas dos relacionamentos afetivo-sexuais. Caderno de Saúde Pública, 22(7), $1375-1384$

Lei n. 8069, de 13 de julho de 1990. (1996). Estatuto da Criança e do Adolescente - ECA. São Paulo: Governo do Estado de São Paulo.

L'Engle, K. L., Brown, J. D., \& Kenneavy, M. A. (2006). The mass media are an important context for adolescents' sexual behavior. Journal of adolescence health, 38, 186-192.

Levisky, R. B. (1998). O que a sociedade atual espera dos jovens. O que os jovens esperam da sociedade. Um grupo de reflexões. In D. L. Levisky (Org.), Adolescência: pelos caminhos da violência: a psicanálise na prática social (pp. 173-188). São Paulo: Casa do Psicólogo.

Martins, P. O., Trindade, Z. A., \& Almeida, A. M. O. (2003). O ter e o ser: representações sociais da adolescência entre adolescentes de inserção urbana e rural. Psicologia Reflexão e Crítica, 16(3), 555-568.

Matos, M., Féres-Carneiro, T., \& Jablonski, B. (2005). Adolescência e relações amorosas: um estudo sobre jovens de camadas populares cariocas. Interação em Psicologia, 9(1), 21-33.

Minayo, M. C. S. (1994). O desafio do conhecimento: pesquisa qualitativa em saúde. São Paulo: Hucitec; Rio de Janeiro: Abrasco.

Moscovici, S. (2004). Representações sociais: investigações em psicologia social. Petrópolis, RJ: Vozes.

Nicolaci-da-Costa, A. M. (2005). Sociabilidade virtual: separando o joio do trigo. Psicologia \& Sociedade, 17(2), 50-57.

Nobrega, S. M., Fontes, E. P. G., \& Paula, F. M. S. M. (2005). Do amor e da dor: representações sociais sobre o amor e o sofrimento psíquico. Estudos de psicologia (Campinas), 22(1), 77-87.

Oliveira, D. C., Gomes, A. M. T., Marques, S. C., \& Thiengo, M. A. (2007). "Pegar", "ficar" e "namorar": representações sociais de relacionamentos entre adolescentes. Revista Brasileira de Enfermagem, 60(5), 497-502.

Oliveira, M. C. S. L. (2006). Identidade, narrativa e desenvol- 
vimento na adolescência: uma revisão crítica. Psicologia em Estudo, 11(2), 427-436.

Osorio, L. C. (1992). Adolescente hoje ( $3^{\mathrm{a}}$ ed.). Porto Alegre: Artes Médicas.

Outeiral, J. O. (1994). Adolescer: estudos sobre adolescência. Porto Alegre: Artes Médicas.

Paiva, V., Calazans, G., Venturi, G., \& Dias, R. (2008). Idade e uso de preservativo na iniciação sexual de adolescentes brasileiros [Versão eletrônica]. Revista de Saúde Pública, 42(1), 45-53.

Palácios, J. \& Oliva, A. (2004). A adolescência e seu significado evolutivo. In C. Coll, J. Palácios, \& A. Marchesi (Orgs.), Desenvolvimento psicológico e educação: psicologia evolutiva

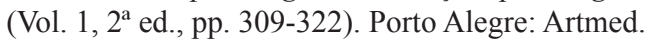

Pereira, A. (1982). Vida íntima: enciclopédia do amor e do sexo. São Paulo: Abril Cultural.

Piaget, J. \& Inhelder, B. (1976). Da lógica da criança à lógica do adolescente. São Paulo: Pioneira.

Rieth, F. (2002). A iniciação sexual na juventude de mulheres e homens. Horizontes Antropológicos, 8(17). 77-91.

Saavedra, L., Nogueira, C., \& Magalhães, S. (2010). Discursos de jovens adolescentes portugueses sobre sexualidade e amor: implicações para a educação sexual. Educação e Sociedade, 31(110), 135-156.

Saldanha, A. A. W., Carvalho, E. A. B., Diniz, R. F., Freitas, E. S., Felix, S. M. F., \& Silva, E. A. A. (2008). Comportamento sexual e vulnerabilidade à AIDS: um estudo descritivo com perspectiva de práticas de prevenção. DST-Jornal Brasileiro de doenças sexualmente transmissíveis, 20(1), 36-44.

Silva, S. G. (2006). A crise da masculinidade: uma crítica à identidade de gênero e à literatura masculinista. Psicologia, Ciência e Profissão, 26(1), 118-131.

Silva, S. P. (2002). Considerações sobre o relacionamento amoroso entre adolescentes. Cadernos CEDES, 22(57), 23-43.
Spink, M. J. (2004). Produção de sentido no cotidiano: uma abordagem teórico-metodológica para a análise das práticas discursivas. In M. J. Spink (Org.), Práticas discursivas e produção de sentido no cotidiano: aproximações teóricas e metodológicas ( $3^{\mathrm{a}}$ ed., pp. 41-61). São Paulo: Cortez.

Traverso-Yepez, M. A. \& Pinheiro, V. S. (2002) Adolescência, saúde e contexto social: esclarecendo práticas. Psicologia \& Sociedade, 14(2), 133-147.

Recebido em: 11/05/2010

1a. Revisão em: 08/08/2010

2a. Revisão em: 15/12/2011

Aceite em: 02/05/2012

Vanuzia Costa é Graduada em Psicologia pela Faculdade Pio Décimo, aluna especial do mestrado em Psicologia da UFS. Email: vanuzia-costa@hotmail.com

Sheyla Christine Santos Fernandes é Mestre em Psicologia Social pela UFPB, Doutora em Psicologia Social na UFBA, Professora Adjunta de Psicologia da UFAL. Endereço: UFAL - ICHICA. Av. Lourival Melo Mota, s/n. Tabuleiro do Martins. Maceio/AL, Brasil. CEP 57072-970. Email: sheylacsfernandes@msn.com

\section{Como citar:}

Costa, V. \& Fernandes, S. C. S. (2012). O que pensam os adolescentes sobre o amor e o sexo? Um estudo na perspectiva das representações sociais. Psicologia \& Sociedade, 24(2), 391-401. 